\title{
O SURGIMENTO DO BIOMA CERRADO ${ }^{1}$
}

\author{
L'ÉMERGENCE DU BIOME CERRADO
}

\section{THE EMERGENCE OF THE CERRADO BIOME}

\author{
Catherine Aubertin \\ Doutora em Economia pela Université de Paris IX (Paris-Dauphine), U.P. IX, França \\ Diretora de pesquisa do IRD, Institut de recherche pour le développement, França \\ Professora visitante do Instituto de Estudos Socioambientais IESA-UFG \\ SQS 310, Bloco I, Apto 305 \\ 70363-090 - Brasilia DF \\ E-mail: catherine.aubertin@ird.fr
}

\begin{abstract}
Resumo
Este artigo analisa como o Cerrado se tornou um desafio ambiental e político até vir a ser um tipo de laboratório para o desenvolvimento sustentável, já que o Brasil visa conciliar seu papel de grande produtor de alimentos e de defensor do meio-ambiente. Estudar o surgimento do Bioma Cerrado permite ilustrar as novas representações da biodiversidade e da conservação que se impõem conforme pesquisas científicas, interesses econômicos, relações de poder Norte-Sul e movimentos sociais. Os compromissos internacionais para reduzir as emissões de gases de efeito estufa; o avanço da cana-de-açúcar para a produção de energia; os serviços ambientais; a afirmação dos povos do Cerrado; a dinâmica entre a Amazônia e o Cerrado... são todos os tópicos tratados neste artigo e envolvidos na construção do Bioma Cerrado.
\end{abstract}

Palavras-chave: Biodiversidade, política de conservação, serviços ambientais, Cerrado.

\section{Résumé}

Cet article analyse comment le Cerrado est devenu un enjeu environnemental et politique jusqu'à devenir une sorte de "laboratoire" du développement durable, le Brésil visant à concilier son rôle de grand producteur d'aliments et de défenseur de l'environnement. Étudier l'émergence du biome Cerrado permet d'illustrer les nouvelles représentations de la biodiversité et de la conservation qui s'imposent au gré des recherches scientifiques, des intérêts économiques, des rapports de force Nord-Sud et des mouvements sociaux. Les engagements internationaux de réduction des émissions de gaz à effet de serre ; l'avancée de la canne à sucre pour la production d'énergie ; les services écosystémiques ; l'affirmation des peuples du Cerrado ; les dynamiques entre Amazonie et Cerrado... sont autant de sujets traités dans cet article qui participent à la construction du biome Cerrado.

Mots clés : Biodiversité, politiques de conservation, services écosystémiques, Cerrado.

\footnotetext{
${ }^{1}$ Agradeço pela tradução de Jéssica Beleza Viana.

Este artigo é um dos resultados do programa Apropriação do território e dinâmicas socioambientais no Cerrado: biodiversidade, biotecnologia e saberes locais apoiado pelo CNPq ( $\left.\mathrm{n}^{\circ} 400361 / 2009-4\right)$ e desenvolvido em parceria franco-brasileira no Instituto de Estudos Socioambientais da Universidade Federal de Goiás.
} 


\begin{abstract}
This paper analyzes how the Cerrado became an environmental and political challenge and also a sort of laboratory for sustainable development, now that Brazil seeks to reconcile its role as major food producer and environmentalist. Studying the emergence of the Cerrado biome illustrates the new biodiversity and conservation representations according to scientific researches, economic interests, North-South power relations and social movements. The international commitments to reduce the emissions of greenhouse gases; the advance of sugarcane plantations for energy production; ecosystem services; the affirmation of the peoples of the Cerrado; the dynamics between the Amazon and Cerrado... are all topics covered in the following paper and involved in the construction of the Cerrado biome.
\end{abstract}

Keywords: Biodiversity, conservation policies, ecosystem services, Cerrado.

\title{
Introdução
}

O Bioma Cerrado surgiu como um desafio político e ambiental na cena internacional no fim de 2009, na Conferência de Copenhague sobre Mudanças Climáticas (COP-15). O Cerrado não era incluso na agenda internacional do Brasil. Enquanto o controle do desmatamento na Amazônia há muito tempo tem sido objeto de múltiplas pressões, políticas, mas também econômicas, com grandes financiamentos internacionais em jogo, poucos participantes conheciam Cerrado. Eles ficaram surpresos com os compromissos voluntários assumidos pelo Presidente Lula sobre este bioma.

Naquela ocasião, o Bioma Cerrado tornou-se emblemático no discurso político do Brasil, que busca conciliar os compromissos virtuosos em favor do meio ambiente. $\mathrm{O}$ mesmo foi observado durante as negociações da Convenção sobre Diversidade Biológica (CDB) e da Convenção sobre o Clima (CQNUMC), e na política agressiva de desenvolvimento agrícola. É de fato no Cerrado, o campeão do agronegócio e do desmatamento, onde se afirmam as contradições entre desenvolvimento econômico e conservação.

Estudar o surgimento do bioma Cerrado nos permite ilustrar as novas representações da biodiversidade e da conservação. As representações da biodiversidade se impõem de acordo com pesquisas científicas, interesses econômicos, relações de poder Norte-Sul, mobilizações dos cidadãos e movimentos sociais. Exemplo disto é o foco dado pela Convenção sobre Diversidade Biológica em seu terceiro objetivo, que é a repartição justa e equitativa dos benefícios decorrentes da exploração dos recursos 
genéticos (AUBERTIN, PINTON, BOISVERT, 2007). A abordagem sobre a biogeodiversidade e singularidade sociocultural (ALMEIDA, 2005), assim como o atual entusiasmo pela perspectiva dos serviços ambientais (GOMEZ-BAGGETHUM et al., 2010) para definir as políticas de proteção da natureza são outros exemplos.

O bioma Cerrado aparece então como o resultado de uma extensão das formas de socialização do ser vivo - ciências, técnicas, conhecimentos - em um espaço geográfico e político onde os usos do solo já estão conflituosos (regressão da pequena agricultura, expansão do agronegócio, áreas dedicadas à conservação vs áreas dedicadas à produção...). Apesar das controvérsias políticas e sociais relacionadas à reconfiguração mercadológica da natureza, ele já nasce com os mecanismos legislativos e econômicos que permitem atingir os objetivos das políticas públicas. Seria o Cerrado é "o laboratório" do desenvolvimento sustentável com o jeito brasileiro?

Para compreender o surgimento do bioma Cerrado, vamos refazer aqui sua história forjada pelas políticas produtivistas e, mais recentemente, pela sensibilidade ambiental, que lhe atribui riqueza ecológica e ameaças de destruição. Questionaremos a utilização redutora do termo bioma que marginaliza a contribuição da população e suas relações ambíguas com a Amazônia.

\section{Um Cerrado dedicado à produção}

Até os anos 1970, o Cerrado, com seu solo pobre e seu isolamento dos canais de comunicação, foi alvo de poucas cobiças. Era uma zona indefinida, o que restava do Brasil se retirássemos as zonas de ocupação econômica dinâmica do Sul e Sudeste, as áreas estagnadas do Nordeste e a floresta amazônica. A ferrovia chegou a Anápolis em 1935 e Goiânia foi fundada no ano seguinte. O slogan "Marcha para o Oeste", lançado pelo governo populista de Getúlio Vargas em 1939, incentivou parte dos fluxos migratórios em direção ao Planalto Central. Assim foi criada a Colônia Agrícola Nacional de Goiás, Ceres, por decreto presidencial em 1941, nas raras terras roxas próprias para a agricultura da região. Tratava-se de ocupar a fronteira, mas também de possibilitar que os pequenos agricultores tivessem acesso à propriedade (FERREIRA, 1988). A criação da nova capital federal, Brasília, resultou na abertura da área por volta de 1960. 
A ocupação intensiva do Cerrado como fronteira agrícola veio mais tarde, com a modernização da agricultura. A soja começou a ser cultivada intensivamente a partir de 1970, quando sua produção passou de 1,5 milhão de toneladas para 15 milhões entre 1970 e 1980. Foi somente no início dos anos 1980 que os solos pobres e ácidos e de baixa produtividade foram corrigidos com a adição de calcário e fertilizantes em larga escala. As vantagens do Cerrado se devem às grandes áreas planas, próprias para a mecanização e a monocultura, com solos profundos bem drenados e uma precipitação média (1500 mm) concentrada em uma estação de chuvas de seis meses.

As especulações são grandes: espera-se que o Cerrado ofereça 50 milhões de hectares para a produção de grãos, ou seja, o dobro das terras dedicadas à agricultura em todo o país (AUBERTIN, 1988). O governo está multiplicando os incentivos à exportação e o acesso ao crédito. Os programas de produção intensiva com base no desmatamento do Cerrado por pequenos agricultores aconteceram durante o período militar, com seus diversos slogans: "Integrar para não entregar!"; "Plante que João (o Presidente Figueiredo) garante!"’. As cobiças internacionais começaram a transparecer: o PROCEDER é um programa de desenvolvimento dos Cerrados destinado a produzir para exportação a soja, o milho e o trigo; financiado pelos japoneses, ele vai alcançar mais de 300.000 ha.

As pesquisas realizadas pela EMBRAPA não se contentam mais em corrigir o solo, elas promovem a aplicação de alta tecnologia em uma agricultura "científica" adaptada aos novos parâmetros de competitividade (seleções de novas variedades, biotecnologia com melhoramento genético e OGM, trabalho do solo). Cada um tem em mente essas imagens da colheita de soja no Mato Grosso: cerca de vinte tratores dispostos em formação de esquadrilha avançando nos infinitos campos de soja. O cultivo da soja transgênica foi autorizado no Brasil em 2004; ele abrange três quartos das áreas plantadas em 2011. As terras da agricultura familiar e pecuária são arrendadas por grandes empresas do agronegócio.

A cana-de-açúcar viu nos últimos anos um novo impulso à produção de etanol, principalmente para o mercado interno, e mantém um movimento de fronteira do sudeste para o noroeste. Ela é encontrada em terras dedicadas à pecuária extensiva muito pouco produtiva, mas também pode substituir terras cultivadas por soja e se beneficiar de solos já corrigidos. A cana é considerada responsável pelo intenso 
desmatamento das terras do Cerrado. Entre 2005 e 2007, o número de usinas de açúcar e etanol dobrou no Goiás, onde havia até então 47 usinas em funcionamento e 56 esperando autorização (CASTRO, 2007). Estas usinas modernas multiplicam as certificações, sejam elas ligadas aos processos industriais ou às normas sociais e ambientais. A colheita é mecanizada para reduzir a emissão de $\mathrm{CO}_{2}$ decorrente da queima na colheita manual. Elas dispõem de laboratórios biológicos de controle de insetos, utilizando a adubação verde derivada dos bagaços de cana para proteger o solo. Há rotação de culturas com leguminosas produzidas pela agricultura biológica. É uma agricultura de precisão que utiliza uma centena de variedades de canas adaptadas a cada condição geomorfológica de manejo. Hoje, as usinas novas não produzem mais açúcar como prioridade, mas são destilarias que utilizam a biomassa das canas para a produção de etanol e energia elétrica. Graças à cogeração de energia, essas usinas contribuem para a eletrificação regional e poderão ser elegíveis aos créditos de carbono.

Hoje, o Brasil é o segundo maior exportador mundial de soja e líder na produção de biocombustíveis. De acordo com a EMBRAPA, o Cerrado é responsável por $70 \%$ da carne bovina (60 milhões de cabeças de gado), $60 \%$ da soja e $48 \%$ do café produzidos no Brasil.

É compreensível, então, a utilização política desta produção limpa e científica. Em junho de 2008, na reunião da FAO sobre "Segurança alimentar, mudanças climáticas e bioenergia", o presidente Lula denunciou os países industrializados que responsabilizam a produção de biocombustíveis pela crise alimentar. Ele elogiou a produção de etanol a partir da cana-de-açúcar que gerou empregos e proporcionou energia limpa e renovável. Ele ressaltou ainda: "Vejo com indignação que muitos dos dedos apontados contra a energia limpa dos biocombustíveis estão sujos de óleo e de carvão. Vejo com desolação que muitos dos que responsabilizam o etanol - inclusive o etanol da cana-de-açúcar pelo alto preço dos alimentos são os mesmos que há décadas mantêm políticas protecionistas, em prejuízo dos agricultores dos países mais pobres e dos consumidores de todo o mundo" ${ }^{\prime 2}$. Ele insiste no fato de que a cana é produzida de maneira ecológica e não ameaça a Amazônia. O Brasil irá exercer grande pressão para que a questão dos

${ }^{2}$ http://grupobeatrice.blogspot.com/2008/06/discurso-do-presidente-lula-na-fao-roma.html 
biocombustíveis não seja abordada no âmbito da Convenção sobre Diversidade Biológica da COP9 em Bonn.

\section{Um bioma rico e recentemente reconhecido}

A construção de um objeto ambiental passa pela comprovação de sua riqueza em biodiversidade e pelos serviços ambientais que ele fornece (abastecimento de água, sequestro de carbono), mas também pela situação de urgência que requer medidas de conservação. A importância dos números -medidas, as ferramentas utilizadas - é determinante para explicar tanto o processo biológico como a valorização econômica.

\section{Uma rica biodiversidade}

O Cerrado obviamente não era um ecossistema ignorado. Ele havia sido objeto de várias expedições de reconhecimento por parte dos pesquisadores naturalistas desde Saint-Hilaire, quem, no início do século XIX, havia coletado 15.000 espécies de plantas e animais dos quais 1.000 eram ainda desconhecidos (SAINT-HILAIRE, 1975). Mas foi a partir do ano de 2000, com os teóricos da ecologia global e as campanhas de defesa do ambiente orquestradas pelas grandes ONGs, que o Cerrado é reconhecido como um ecossistema notável, como um dos centros mundiais de biodiversidade. Um "novo mapa da vida na Terra" surge como ferramenta a serviço da conservação (OLSON et al., 2001). As agências de financiamento passaram a privilegiar o nível eco regional como a escala de intervenção. O Cerrado é de fato parte de um dos 25 hotspots identificados em 2000 no artigo de Myers et al. e dos 34 hotspots hoje consagrados pela Conservation International (2011). Ele também faz parte das 200 Global ecoregions do WWF, outra classificação biogeográfica concorrente proposta em 2001. O Cerrado é designado como o ecossistema de savana mais diversificado do mundo, abrigando 5\% da biodiversidade global.

A riqueza de sua biodiversidade vem em parte da grande variedade de ambientes naturais, que vão desde campos limpos a savanas arbóreas. Seria mais certo falar de Cerrados no plural. Pode-se distinguir 23 tipos de vegetação que compõem mosaicos de habitats e paisagens, enriquecidas por sua proximidade com as fronteiras de outros biomas: Caatinga, Mata Atlântica, Pampa, Pantanal e Amazônia. 
Suas muitas espécies endêmicas são adaptadas à seca que dura metade do ano e às regulares queimadas naturais ou controladas. Assim o Cerrado abriga 10.000 plantas (com uma alta taxa de endemismo: 44\%), 195 espécies de mamíferos (7,2\%), 607 espécies de aves (2,8\%), 225 espécies de répteis, 186 de anfíbios (14,7\% e 15,1\%) e 800 espécies de peixes (25\%) (CONSERVATION INTERNATIONAL, 2011).

\section{Um bioma ameaçado}

A sucessão de fronteiras agrícolas enfraqueceu o ecossistema do Cerrado. Sua taxa de desmatamento tornou-se uma questão internacional, mas também deu margem para uma reflexão sobre as relações com a Amazônia e sobre o projeto brasileiro de território em geral.

\section{A taxa de desmatamento se torna uma questão internacional}

No fim de dezembro de 2009, o Brasil, quarto maior emissor de gases de efeito estufa devido ao desmatamento ${ }^{3}$, apresentou na Conferência das Partes em Copenhague um ambicioso programa de redução de emissões para o Secretariado da Convenção sobre Mudança do Clima (CQNUMC): redução de 36,1\% a 38,9\% do equivalente $\mathrm{CO}_{2}$ até 2020 associada a uma redução de 80\% na taxa de desmatamento da Amazônia Legal em 2020 em relação ao período entre 1996 e 2005, uma redução de 40\% para o Bioma Cerrado em relação ao período entre 1999 e 2005, uma duplicação das plantações florestais de 5,5 a 11 milhões de hectares em 2015, a recuperação de 15 milhões de hectares de pastagens degradadas, etc. ${ }^{4} \mathrm{O}$ Brasil coloca sua luta contra o desmatamento ilegal no centro de sua estratégia de combate contra a mudança climática.

Se este compromisso pela Amazônia já era esperado, o compromisso voluntário pelo Cerrado surpreendeu. As declarações do presidente Lula em Copenhague foram a

\footnotetext{
${ }^{3}$ Em 2005, as mudanças no uso do solo e das florestas no Brasil representavam $77 \%$ das emissões de $\mathrm{CO}_{2}$. Se calcularmos a parte das mudanças no uso do solo e das florestas em relação a todas as emissões de gases de efeito estufa (GEE) do Brasil em $\mathrm{CO}_{2}$ equivalente seu percentual é de $67 \%$ ou 57\%, dependendo do método de conversão utilizado. (Ministério da Ciência e Tecnologia, 2010).

${ }^{4}$ Estes compromissos estão na forma de uma lei, de 29 de dezembro de 2009, que estabelece a política nacional sobre a mudança climática e também de um decreto de 09 de dezembro de 2010, que determina os cálculos (Presidência da República, 2010).
} 
oportunidade de descobrir dois fenômenos: a desaceleração do desmatamento na Amazônia e a situação desastrosa do Cerrado. Provavelmente para dar mais abrangência à argumentação em favor do Cerrado e para denunciar o que é percebido como uma discriminação, a Amazônia serve de ponto de comparação de forma sistemática. $O$ objetivo de reduzir em $40 \%$ a taxa de desmatamento ${ }^{5}$ no Cerrado parece mais ambicioso do que o de $80 \%$ estipulado para a Amazônia.

A Amazônia Legal abrange pouco mais de quatro milhões de $\mathrm{km}^{2}$, dos quais 15\% (14,54\% em 2009 ou $\left.739.928 \mathrm{~km}^{2}\right)$ já foram desmatados. O Cerrado ocupa uma área de 2 milhões de $\mathrm{km}^{2}$, o que representa a metade da Amazônia Legal. Em 2008, 986.247 ha, ou 48,37\% de sua cobertura original já foi desmatada (IBGE, 2010).

Os objetivos definidos em Copenhague dependem obviamente das situações de referência escolhidas para facilitar o cumprimento das metas. Assim, a estimativa para 2020 é calculada a partir de uma média de desmatamento anual da Amazônia no período entre 1996-2005, que é de $19.535 \mathrm{~km}^{2}$. A redução de $80 \%$ do desmatamento, o que representa uma área de $3.900 \mathrm{~km}^{2}$ (Presidência da República, 2010), era um objetivo que estava prestes a ser alcançado, pois, depois de um pico em $2004\left(27.423 \mathrm{~km}^{2}\right.$, 0,54\%), a tendência era um declínio regular. Em 2009, a taxa observada foi de 0,14\% $\left(7.000 \mathrm{~km}^{2}\right.$ ) (IBGE, 2010). Observa-se um aumento do desmatamento, que em 2010 atingiu cerca de $5.500 \mathrm{~km}^{2}$, acarretado pela implementação de novas práticas de degradação (para escapar dos satélites de vigilância, os cortes são mais dispersos, em áreas menores que $25 \mathrm{ha}$ ) e, de forma mais alarmante, às expectativas da reforma do Código Florestal ${ }^{6}$.

Uma mesma tendência à desaceleração é observada no Cerrado, onde os desmatamentos passaram de $18.000 \mathrm{~km}^{2}$ em média entre 1994 e 2002 para $14.000 \mathrm{~km}^{2}$ entre 2003 e 2008. Usando os dados da Fundação de Ciência, Aplicações e Tecnologia Espacial (FUNCATE) sobre o período entre 1999-2008, o governo brasileiro projeta um desmatamento de $15.700 \mathrm{~km}^{2}$ até 2020 dos quais pretende reduzir $40 \%$ ou seja, 9.500 km2 (Presidência da República, 2010). Este objetivo ambicioso corre o risco de não ser

\footnotetext{
${ }^{5}$ Não se pode falar propriamente de 'desmatamento' no Cerrado. Trata-se principalmente de generalização da prática de queimadas tanto pelas grandes empresas como por pequenos produtores.

${ }^{6}$ Segundo o Instituto Nacional de Pesquisas Espaciais (INPE) o desmatamento aumentou 27\% entre agosto de 2010 e abril de 2011.
} 
atingido se a reforma do Código Florestal isenta os pequenos proprietários de manterem sua Reserva Legal ${ }^{7}$. Existem 773.848 pequenos agricultores (79,4\% das explorações) no Cerrado e ocupam 32.884.159 ha (19\% do Cerrado). Assim, 8 milhões de hectares perderiam seu status de proteção (IPEA, 2011).

\section{Um destino cruzado: Cerrado/ Amazônia}

Notamos que nos últimos anos, o desmatamento do Cerrado, em termos absolutos, foi duas vezes maior do que o da Amazônia. Há várias explicações. Podemos começar lembrando que a área de Reserva Legal, que corresponde à obrigação de cada propriedade de conservar uma porção de terra na sua vegetação nativa definida pelo Código Florestal, é de $80 \%$ na floresta amazônica, de $35 \%$ nas terras do Cerrado localizadas na Amazônia Legal e de $20 \%$ nas outras regiões, que abrangem a totalidade das terras dos Cerrados do Centro-Oeste. Do ponto de vista legal, o Cerrado não é tão protegido como a Amazônia. De fato, somando as Unidades de Conservação (UC) e as Terras indígenas, cerca de 50\% do território amazônico está sob proteção, enquanto estima-se que $8,24 \%$ do Cerrado é protegido por meio de UC federais e estaduais, e 4,39\% por meio de Terras indígenas homologadas (PP Cerrado, 2010).

Além disso, após o pico de desmatamento de 2004, um Plano de Ação para Prevenção e Controle do Desmatamento na Amazônia Legal foi promulgado (foi preciso esperar até 2010 para implementar um plano desse tipo no Cerrado). É difícil calcular a eficácia desse plano governamental, mas pode-se avaliar a iniciativa conhecida sob o nome de Moratória da Soja. Em julho de 2006, o setor privado se pronunciou pela proteção da Amazônia. A Associação Brasileira da Indústria de Óleos Vegetais (ABIOVE) e a Associação Brasileira dos Exportadores de Cereais (ANEC) se comprometeram a não comercializar soja proveniente do desmatamento da Amazônia. Grandes empresas como a Cargill concentram a expansão de sua produção no Cerrado. No entanto, o governo emitiu um decreto em 2009 ( $\mathrm{n}^{\circ}$. 6.961), que aprova o zoneamento agroecológico da cana-de-açúcar. Foram identificados 63.480 .000 hectares

\footnotetext{
${ }^{7}$ A área máxima de um pequeno produtor é estipulado em 4 módulos fiscais, unidade do cadastro rural que varia conforme áreas de 5 a 110 hectares.
} 
aptos para sua expansão, a grande maioria no Cerrado. Este mesmo decreto proíbe a expansão da cana na Amazônia, no Pantanal e na Bacia do Alto Paraguai.

O Cerrado é consagrado como celeiro moderno do Brasil e tornou-se o escudo da Amazônia. As vozes se elevam para defender o Cerrado: a alta taxa de desmatamento ameaça dois serviços ambientais, que são o sequestro de carbono e o abastecimento de água.

\section{Serviços ambientais estratégicos}

Desde a Cúpula da Terra no Rio (1992), os recursos naturais da biodiversidade têm sido considerados sob a perspectiva do desenvolvimento sustentável e, mais recentemente, em função dos serviços ambientais oferecidos pelos ecossistemas. $\mathrm{O}$ Cerrado poderia ser tão importante em termos de serviços ambientais quanto em termos de produção agrícola?

As políticas de criação de áreas protegidas e as diversas leis destinadas ao controle do desmatamento não têm dado os resultados desejados. Ao mesmo tempo, o fato de considerar a biodiversidade como um provedor de serviços ambientais favoreceu a implementação de uma visão econômica da natureza e do desenvolvimento de mecanismos econômicos para a conservação. Deste modo, os ecossistemas são vistos como prestadores de serviços (armazenamento e sequestro de carbono, bem como a manutenção da biodiversidade, fonte de alimentos e renda para as populações locais, regulação dos regimes hídricos, etc.) serviços estes que devem ser financiados no intuito de internalizar os custos ambientais que até então não eram considerados pelo sistema de preços. Assim, os mecanismos de Redução de Emissões do Desmatamento e Degradação Florestal (REDD) nos países em desenvolvimento tornaram-se um dos maiores desafios na Convenção sobre Mudança do Clima. Graças a eles, seria possível transformar o carbono armazenado e capturado pelas florestas tropicais em créditos que poderiam ser utilizados para compensar a crescente poluição industrial dos países do Norte. Assim, as florestas aparecem como um mecanismo de flexibilidade para reduzir as emissões de gases de efeito estufa por meio da criação de um mercado, ou ao menos de uma bolsa de troca, de créditos de carbono. 


\section{Os fluxos de carbono de uma Amazônia "ao contrário"}

Associam-se os incêndios florestais responsáveis pela emissão de $20 \%$ das emissões de gases de efeito estufa à imagem da Amazônia em chamas. No entanto, os ecossistemas de savanas deveriam logicamente também ser considerados.

Assim, o Cerrado é muitas vezes apresentado como uma Floresta Amazônica "ao contrário". Isto significa que, diferentemente da Amazônia, sua biomassa, seu potencial de captura de carbono, provém de seu sistema radicular bastante desenvolvido devido às condições de seca e incêndios regulares, enquanto a sua parte aérea é reduzida. O Painel Intergovernamental sobre Mudança do Clima (IPCC) estima o estoque de carbono do Cerrado em 29 t/ha na vegetação aérea e em 117 t/ha de carbono orgânico no solo, até um metro de profundidade, o que corresponde a $80 \%$ da biomassa abaixo do solo (contra 21\% na Amazônia).

O Plano de Ação para Prevenção e Controle do Desmatamento e das Queimadas no Cerrado, o PP Cerrado (SERVIÇO PÚBLICO FEDERAL, 2010), utilizando as estimativas do Ministério da Ciência e Tecnologia (MCT), mostra que as emissões de gases de efeito estufa devidas à mudança no uso do solo no Cerrado (áreas de desmatamento, excluindo-se as terras abandonadas) estão em crescimento considerável: 189 milhões de toneladas em 1990 (contra 410 para a Amazônia), 379 milhões de toneladas em 2005 (contra 714 na Amazônia).

Donald Sawyer (2009) vai mais longe. Ele mostra que, devido à desaceleração do desmatamento da Amazônia e o fato de que a área desmatada no Cerrado é quase o dobro do que na Amazônia, atualmente o Cerrado emite mais $\mathrm{CO}_{2}$ na atmosfera do que a Amazônia. Se considerarmos a emissão de óxido nitroso $\left(\mathrm{N}_{2} \mathrm{O}\right)$, devida à utilização de fertilizantes, de pesticidas e de metano (dois gases com poder de aquecimento muito maior do que o $\mathrm{CO}_{2}$ ) no agronegócio e na pecuária e observarmos o ciclo de vida dos produtos (adubos comprados na Rússia, grãos exportados para a China), a contribuição do Cerrado para as emissões de gases de efeito estufa é significativa.

No momento, estes mecanismos REDD são utilizados nos ecossistemas florestais e o Cerrado, apesar de sua contribuição significativa para gestão de carbono, não pode se beneficiar destes incentivos, o que é visto como mais uma discriminação do Cerrado em relação à Amazônia. 
A caixa d'água do Brasil

Um outro serviço ambiental reconhecido do Cerrado é ser a caixa d'água do Brasil. O Cerrado ocupa $24 \%$ da superfície do país. Ele cobre totalmente ou em parte 11 estados do Brasil, do Paraná ao Piauí, e o Distrito Federal, ou seja, cerca de 1.500 municípios abrigando 25 milhões de habitantes, principalmente urbanos (83\%). Suas 20.000 fontes irrigam 6 das 12 regiões hidrográficas do país, com um papel crucial para o abastecimento de água no Pantanal. As bacias dos grandes rios Paraná, TocantinsAraguaia, São Francisco e Paraguai são alimentadas principalmente pelas fontes do Cerrado $^{8} .9$ entre 10 brasileiros usam a eletricidade hidráulica fornecida pelas águas do Cerrado. A Barragem de Tucuruí, no Pará, tem $70 \%$ de sua água fornecida pelo Cerrado, e a de Itaipu, no Paraná, 50\%.

A Agência Nacional de Águas (ANA, 2011) dividiu o Cerrado em 679 bacias hidrográficas. E o alarme soa: $62,1 \%$ possuem uma taxa de desmatamento que contribui para reduzir o suprimento de água. As agriculturas intensivas também são responsáveis por um consumo excessivo de água. Há, por exemplo, 7.000 pivôs centrais no Cerrado, cuja irrigação utiliza 70\% dos recursos hídricos.

\section{Os mecanismos econômicos para a conservação do Cerrado}

Os organismos dos Estados do Cerrado responsáveis pelo meio ambiente não esperaram a generalização dos mecanismos REDD para incluir em suas políticas de conservação mecanismos econômicos para superar os limites do Código Florestal ou das áreas protegidas. Assim, em 2003, a Agência Ambiental de Goiás (AGMA) organizou, com o apoio do Banco Mundial, a comercialização dos direitos de exploração florestal entre agentes privados. Trata-se de promover a compensação da Reserva Legal para além da propriedade; esta deve respeitar as Áreas de Preservação Permanente (APP) e ser produtiva. Sob essas condições, o proprietário pode efetuar uma compensação de $25 \%$ de sua reserva legal na mesma microrregião e $30 \%$ fora da

${ }^{8} 52,2 \%$ das fontes de alimentam o rio Paraná vêm do Cerrado, 83,6\% para o Tocantins, 52,3\% para o São Francisco e 87,4\% para o Paraguai. 
microrregião, mas sempre na mesma bacia hidrográfica. De 2003 a 2005 foram observados 34.000 ha em 303 transações. A vantagem é que, de um lado, o proprietário não tem que pagar os altos custos de restauração de sua Reserva Legal e pode se dedicar às suas atividades produtivas, e por outro lado, as terras não desmatadas passam a ter um valor no mercado que cresce com a sua conservação (MARTIN, CHAVES, 2008).

Um outro sistema também foi implementado: uma bolsa de troca de DOF, o Documento de Origem Florestal emitido pelo IBAMA, indispensável para transportar e comercializar produtos florestais, como madeira e carvão. Aquele que solicitar uma autorização de exploração florestal além de suas quotas deverá comprar direitos (DOFs não utilizados) em um sistema computadorizado administrado pela Secretaria do Meio Ambiente e dos Recursos Hídricos do Estado de Goiás (SEMARH).

Em 2009, a Secretaria de Assuntos Estratégicos da Presidência da República assinou com a SEMARH um acordo de cooperação técnica para a criação da primeira bolsa de valores de ativos ambientais. As compensações da Reserva Legal, que até então passavam pela compra de terras, agora deverão passar pela troca de direitos de desmatamento em um mercado que cria mecanismos de compensações ambientais para o agronegócio. A Bolsa de Títulos e Ativos Ambientais do Brasil (BTAAB) foi inaugurada em março de 2010 em Goiânia. Em breve, esta bolsa também deverá incluir os créditos de carbono. Seu bom funcionamento vai depender da reforma do Código Florestal, amplamente discutido, bem como de projetos de lei regulando os pagamentos pelos serviços ambientais debatidos no congresso.

Há pouco tempo, a SEMARH lançou uma consultoria para implementar um Sistema de Conservação Ambiental baseado em Mecanismos de Mercado e Diretrizes para o Modelo de Desenvolvimento Econômico de Baixo Carbono no Estado de Goiás. Além disso, será divulgado um decreto de incentivos à criação de Reservas Particulares do Patrimônio Natural (RPPN) que oferecerá Certificados de Reserva Ambiental (CRA) a serem trocados entre donos de RPPN e pessoas que têm obrigação de compensar uma devastação ambiental (desmatamento da reserva legal, por exemplo) em um sistema de bolsa fiscalizado pela SEMARH.

Assim, o Cerrado se destaca na reflexão e na implementação dos mecanismos que deverão acompanhar a reforma do Código Florestal. Este, de fato, ao baixar os padrões de conservação, o percentual de Reserva Legal e a definição das APP, vai abrir 
caminho para ações de compensação e para os mecanismos econômicos que irão definilas. Se a reforma do Código Florestal e o uso de mecanismos econômicos para a conservação da natureza são acirradamente discutidos, até hoje é difícil encontrar uma oposição sociopolítica organizada no Cerrado.

\section{A institucionalização do Cerrado}

A apresentação das riquezas de um ecossistema e das ameaças que ele sofre é pressupõe a apresentação da sociodiversidade e das mobilizações associadas a ele. A Convenção sobre Diversidade Biológica consagrou o vínculo entre diversidade biológica e diversidade cultural. O fato de falar de um único Bioma Cerrado é um indicativo da fraqueza da afirmação dos povos. Em contrapartida, há uma forte institucionalização das iniciativas.

No Cerrado vivem 38 etnias (entre as 200 que o Brasil possui) com 45.000 pessoas (entre os 300.000 índios no Brasil). O Goiás abriga três reservas indígenas, onde a população está em risco: os Avá-Canoeiros, os Tapuias e os Karajá. As coordenações indígenas do Cerrado permanecem modestas e dispersas, sem a força e o reconhecimento da mídia da Coordenação das Organizações Indígenas da Amazônia Brasileira (COIAB), fundada em 1989. O Cerrado também abriga o maior quilombo da América Latina, as terras Kalunga, onde vivem 4.000 pessoas em 230.000 hectares. Além disso, o período militar não promoveu a organização de pequenos produtores e os movimentos mais fortes continuam ligados à Igreja, durante muito tempo pouco atenta às questões ambientais. Nesta época, não existiam organizações semelhantes ao Conselho Nacional dos Seringueiros de Chico Mendes, criado em 1985 para os trabalhadores do extrativismo, ou ao Grupo de Trabalho Amazônico (GTA, uma rede de sindicatos e associações fundada em 1990).

Ao contrário da Amazônia, onde a defesa da floresta passou pelo reconhecimento dos direitos das populações indígenas e locais, de seus conhecimentos sobre a biodiversidade e pelos fortes vínculos com os movimentos ambientalistas internacionais, a defesa organizada do Cerrado parece resultar das iniciativas da "sociedade civil", conduzidas por cientistas e acadêmicos que puderam mobilizar financiamentos internacionais. 
Foi preciso esperar o Fórum Global, um evento alternativo paralelo à Cúpula da Terra no Rio em 1992, para que fosse criada a Rede Cerrado, que aprovou o Tratado dos Cerrados. Sua finalidade é promover o intercâmbio de experiências e informações, visando conciliar justiça social, conservação ambiental e desenvolvimento. Agora ela dispõe de 79 organizações membros e 300 simpatizantes (SWAYER, 2008). A cada dois anos, encontros dos Povos do Cerrado são organizados. Deve-se destacar particularmente o importante papel de coordenação desempenhado pela ONG Instituto Sociedade, População e Natureza (ISPN), criada em 1995 para gerir o programa Pequenos Projetos Eco-sociais (PPP-ECOS), financiado pelo Fundo Global para o Meio Ambiente (GEF) por meio do Small Grant Program (SGP). O ISPN, que tem mais de 300 projetos de apoio às iniciativas locais de valorização dos ativos da biodiversidade, agora é praticamente a única iniciativa dedicada ao bioma (SAWYER, 2008). Houve também, a partir de 1996, as intervenções do Departamento para o Desenvolvimento Internacional na Inglaterra (DFID-UK).

O início de um processo participativo entre acadêmicos e representantes do Ministério do Meio Ambiente, incorporando organizações locais, teve início no seminário Ações Prioritárias para a Conservação da Biodiversidade do Cerrado e do Pantanal em 1998. Várias propostas e planos para o desenvolvimento e proteção do Cerrado foram estabelecidos. O Grupo de Trabalho do Cerrado foi instituído em 2003 em um encontro dos Povos do Cerrado em Goiânia pela Ministra do Meio Ambiente, Marina Silva, no âmbito do Programa Nacional de Conservação e Uso Sustentável do Bioma Cerrado: o Programa Cerrado Sustentável. Este programa, originado na sociedade civil e apoiado pelo projeto GEF Cerrado, que investiu 13 milhões de dólares (e o Brasil, 26 milhões), foi implantado pelo Banco Mundial. Embora o programa inicial tenha sido voltado principalmente para a definição das áreas prioritárias para conservação, utilização sustentável e repartição dos benefícios derivados da biodiversidade, dos territórios das comunidades tradicionais, indígenas e quilombolas, e das áreas sob forte pressão agrícola, as intervenções do Banco Mundial privilegiaram uma abordagem técnica para a agricultura. Elas também aliviaram a dívida dos Estados, o que incentivou a construção de infraestruturas.

A institucionalização do movimento continua com o decreto 5.577/2005 que lança este programa, acompanhado pela criação de uma comissão nacional, a Conacer 
(Comissão Nacional do Programa Cerrado Sustentável). A Conacer reúne membros de ministérios, centros de pesquisa, sindicatos, ONGs e de associações quilombolas e indígenas. Ela está na origem do pedido de emenda à Constituição: para proteger o ecossistema do Cerrado como bioma ameaçado e negligenciado em escala internacional em benefício da Amazônia, a Conacer orquestra uma campanha política e legislativa de defesa do Cerrado e da Caatinga para o reconhecimento desses biomas como constituintes do patrimônio nacional, no mesmo status da Amazônia, do Pantanal e da Mata Atlântica ${ }^{9}$. A expectativa é que o Conselho Monetário Nacional (CMN) estenda ao Cerrado as restrições de crédito para os proprietários que desmatem. Em geral, existe uma reivindicação nacional para não centralizar todas as questões ambientais na Amazônia, como fazem as grandes organizações internacionais.

Finalmente, em 2010, seguindo o modelo do Plano de Ação para Prevenção e Controle do Desmatamento na Amazônia Legal de 2004, o Plano de Ação para Prevenção e Controle do Desmatamento e das Queimadas no Cerrado (PP Cerrado), fruto de uma colaboração entre o Governo Federal e acadêmicos, foi promulgado pelo Serviço Público Federal. O plano apresenta 150 ações integradas com a colaboração de 13 ministérios e do setor privado e voluntário, com acompanhamento regular via satélite. O PP Cerrado prevê a utilização mais ampla do carvão vegetal para as siderúrgicas, a recuperação de áreas degradadas, a luta contra a prática de queimadas e a criação de 2,5 milhões de hectares de áreas protegidas. Ele também apresenta uma contrapartida aos danos causados pelo desvio das águas do rio São Francisco.

Este plano rompe com a visão de pequenos projetos "eco-sociais" desenvolvidos até hoje e também com a visão naturalista apoiada pelas pesquisas acadêmicas financiadas pelo Ministério da Ciência e Tecnologia e pelo Ministério do Meio Ambiente no Cerrado (como por exemplo o Programa Comcerrado, criado em 2007 pela mutualização das pesquisas no Cerrado, ou a proposta de oferta da Rede ProCentro-Oeste em 2010, pelo estabelecimento de uma rede de universidades do CentroOeste).

Mais recentemente, em julho de 2011, na reunião anual da Sociedade Brasileira para o Desenvolvimento da Ciência (SBPC), o Governo reafirma sua confiança nos

\footnotetext{
${ }^{9}$ Projeto de emenda constitucional PEC 115/150 introduzido em 1995, que alteraria o Parágrafo 4 do artigo 225 da Constituição Federal.
} 
cientistas para defender o Cerrado. O Ministro da Integração Nacional anuncia a recriação da SUDECO, Superintendência de Desenvolvimento do Centro-Oeste. O objetivo é eliminar os pontos de estrangulamento causados pela insuficiência das infraestruturas, atenuar as desigualdades socioeconômicas e concentrar os investimentos em inovação tecnológica e conhecimento. É neste dilema, entre crescimento econômico e sustentabilidade socioambiental, que o Cerrado deverá desempenhar um papel crucial.

\section{Conclusão}

Bertha Becker, especialista em geopolítica da Amazônia, agora inclui o Cerrado na sua análise. Ela evoca o confronto de dois modos de ocupação do território fundamentados em formas de produção e ecossistemas distintos: a ocupação atual, pela agricultura e pela expansão pecuária convencional no Cerrado que avança em direção à floresta; e a ocupação que considera o futuro dos ecossistemas florestais e a restauração do Cerrado, graças às novas formas de produção possibilitadas pelas novas tecnologias. A conservação da Amazônia não se opõe à do Cerrado, mas depende dela. O desenvolvimento sustentável de um está ligado ao do outro. O futuro destas duas regiões as torna inexoravelmente solidárias (BECKER, 2010).

Em junho de 2011, na cerimônia de criação do comitê organizador da Conferência sobre Desenvolvimento Sustentável, Rio+20, a Presidente Dilma reafirma sua determinação de vetar o texto da reforma do Código Florestal se este derrubar as medidas de luta contra o desmatamento. Ela reafirma que seu país vai honrar seus compromissos feitos à comunidade internacional quanto à redução do desmatamento. Ela recorda a postura do Brasil quanto ao desenvolvimento sustentável: conciliar seu papel de grande produtor de alimentos e de defensor do meio-ambiente. O Cerrado será parte deste desafio.

\section{Referências}

ALMEIDA, Maria Geralda de (Org.). Tantos Cerrados: múltiplas abordagens sobre a biogeodiversidade e singularidade culturel. Goiânia: Ed. Vieira, 2005. 348 p. 
AUBERTIN, Catherine. (Org.). Fronteiras. Brasília: Editora Universidade de Brasília, 1988. $250 \mathrm{p}$.

AUBERTIN Catherine. PINTON Florence, BOISVERT Valérie. (Ed.). Les marchés de la biodiversité. Editions de l'IRD, 2007. 269 p.

BECKER K. Bertha. Biodiversidade e desenvolvimento da Amazônia Legal. Desafios e opções estratégicas. Ateliê Geográfico, Goiânia, v. 5, n.14, P.324-338, 2011.

CASTRO Selma. Estudo da expansão da cana-de-açúcar no estado de Goiás: subsídios para uma avaliação do potencial de impactos ambientais In: Impactos Econômicos, Sociais e Ambientais no cultivo da Cana-de-açúcar no Território goiano, II FÓRUM DE C\&T NO CERRADO. Goiânia: SBPC, 5 outubro de 2007, P. 8-17.

CONSERVATION INTERNATIONAL, Biodiversity Hotspots. Acessado em 2011: http://www.biodiversityhotspots.org/xp/hotspots/cerrado/Pages/default.aspx

FERREIRA, Ignez, Costa, Barbosa. Ceres e Rio Verde: Dois Momentos da Expansão da Fronteira Agrícola. In: AUBERTIN Catherine (Org.). Fronteiras. Brasília, Editora Universidade de Brasília: 1988. p. 38-59.

GÓMEZ-BAGGETHUN, Erik, GROOT, Rudolf de, LOMAS, Pedro L., MONTES, Carlos. The history of ecosystem services in economic theory and practice: From early notions to markets and payment schemes In: Ecological Economics, Volume 69, Issue 6, p. 1209-1218. 2010.

IBGE. Indicadores de Desenvolvimento Sustentável. Brasil, Estudos \& Pesquisas n ${ }^{\circ}$ 7: 2010. $450 \mathrm{p}$.

IPEA. Código Florestal: implicações do PL 1876/99 nas áreas de Reserva Legal. Brasil, Comunicados do IPEA n 96: 8 de junho de 2011. 22 p.

MARTINS JR. O. P., CHAVES F. T.. Uso de instrumentos econômicos para a conservação da biodiversidade em Goiás: implicações e perspectivas. In FERREIRA Laerte Guimarães (Org.). A encruzilhada socioambiental: biodiversidade, economia e 
sustentabilidade no Cerrado. Goiânia: Editora da Universidade de Goiás, 2008. p. 187198.

MYERS N., MITTERMELER R.A., MITTERMELER C.G., FONSECA, G. da, KENT J., Biodiversity hotspots for conservation priorities. In: Nature, 403, p. 853-858. 2000.

MINISTÉRIO DA CIÊNCIA E DA TECNOLOGIA. Segunda Comunicação Nacional do Brasil à Convenção-Quadro das Nações Unidas sobre Mudança do Clima. Coordenação-Geral de Mudanças Globais do Clima. 2v. Brasília, 2010.

OLSON, D. M., DINERSTEIN, E., WIKRAMANAYAKE, E. D., BURGESS, N. D., POWELL, G. V. N., UNDERWOOD, E.C., D'AMICO, J. A., ITOUA, I., STRAND, H. E., MORRISON, J. C., LOUCKS, C. J., ALLNUTT, T. F., RICKETTS, T. H., KURA, Y., LAMOREUX, J. F., WETTENGEL, W. W., HEDAO, P., KASSEM, K. R.. Terrestrial Ecoregions of the world: A new map of life on Earth In: Bioscience, Volume 51, p. 933-938, 2001.

PRESIDÊNCIA DA REPÚBLICA. Decreto $\mathrm{n}^{\circ}$ 7.390, de 9 de dezembro de 2010.

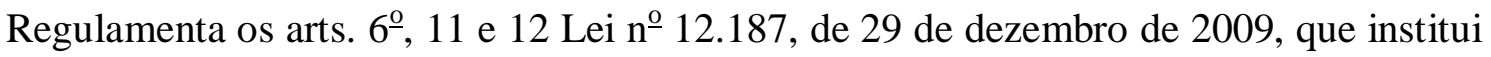
a Política Nacional sobre Mudança do Clima - PNMC, e dá outras providências.

SAWYER, Donald. Fluxos de carbono na Amazônia e no Cerrado: um olhar socioecossistêmico In: Sociedade e Estado, Brasília, v. 24, n. 1, p. 149-171, 2009.

SAWYER Donald, LOBO, Andrea de Souza. O papel da Sociedade no Estabelecimento de Politicas Publicas para as Savanas. In: FALEIRO, Fábio Gelape; FARIAS NETO, Austeclínio Lopes de (Eds.). Savanas: desafios e estratégias para o equilíbrio entre sociedade, agronegócio e recursos naturais. Planaltina: EMBRAPA Cerrados, 2008. Capitulo 39, p.1153-81.

SERVIÇO PÚBLICO FEDERAL. Plano de Ação para prevenção e controle do desmatamento e das queimadas no cerrado. Brasília, setembro de 2010. 165 p. 
SAINT-HILAIRE, Auguste de. Viagem à província de Goiás. Belo Horizonte: Itatiaia Editora, 1975.

Recebido para publicação em agosto de 2012 Aprovado para publicação em setembro de 2012 